\title{
Safety in numbers for Earth Observing System
}

\section{- Industry report offers redesign NASA decries unwanted advice}

\section{Washington}

Officials at the National Aeronautics and Space Administration (NASA) last week attacked a draft report that suggests the space agency may be pursuing a poor design for its planned $\$ 40,000$ million series of climate monitoring satellites, collectively known as the Earth Observing System (EOS).

The report, by three researchers from the space and technology group of California-based TRW Inc., argues that it would be better to construct EOS as orbiting groups of many small, relatively inexpensive satellites, rather than as a few large, multi-purpose platforms, each the size, complexity and cost of the Hubble Space Telescope.

The recent demoralizing failure of the Hubble's optics, along with suggestions that the proposed space station Freedom will require an impossible number of manhours for routine maintenance, has added weight to the criticism that large, complex systems invite disaster. But Ray Roberts, ZOS programme director, said that the unsolicited advice from TRW, which at present has no major contracts for EOS, reflected "vested interests". He warned against "opportunists" and "NASAbashing" in the light of NASA's recent problems.

NASA's plans for EOS put as many as 16 different instruments on each of six large platforms to allow simultaneous observations of regions of interest. But a number of scientists, including James Hansen, director of the Goddard Institute for Space Studies, and members of a American Institute of Aeronautics and Astronautics (AIAA) review panel, have called on NASA officials to rethink the EOS design, arguing that the same scientific results can be achieved more reliably with the tightly-grouped "clusters" of specialized satellites similar to what the TRW report proposes.

The biggest concern is the possibility of a total loss of one of the proposed EOS platforms. All six are to be carried into polar orbits by relatively untried Titan IV rockets, whose predecessor, the Titan III, has suffered failures of varying degree in more than half of its launches over the past five years (see Nature 344, 281; 1990). If EOS were to be built around smaller satellites, they would probably be launched from more reliable Atlas or Delta boosters, NASA officials say.

A breakdown in a critical power, control or data-transmission component of the EOS platforms could render all the on-board scientific instruments useless, critics point out. Shifting the emphasis to small satellites "alleviates the danger of placing all eggs in one basket [and] the possibility of losing all data from one launch or subsystem failure", Hansen writes in a paper scheduled to appear in Issues in Science and Technology this autumn.

With an orbiting group of several simple satellites, even the total failure of any one probe would be likeiy to result in no more than a partial loss of coverage. Small replacement satellites can be built relatively cheaply and quickly, the AIAA panel noted in a report released last month.

Other critics stress the danger of magnetic, electrical and thermal interference between sensitive instruments on a shared platform. And only with small satellites can researchers launch small packages of instruments to take advantage of new technology or to focus on a new area of research. Both Hansen and the AIAA panel note, for example, that because the EOS platforms will be restricted to polar orbits, they will be restricted in their ability to monitor hour-by-hour variations in clouds - a critical deficiency if clouds turn out to be as important to the global warming equation as is now believed. Indeed, Hansen's chief proposal is for additional satellites in both polar and inclined orbits to maximize coverage.

The TRW report says that many of the planned EOS instruments could make simultaneous measurements from small satellites orbiting in formation and separated by distances of three to five kilometres. TRW researchers Carl Graves, Peter Gottlieb and Alan Rosen decided that 24 main instruments of the type proposed for the first three EOS platforms near the end of the decade could be distributed on 17 smaller satellites in several clusters without loss of accuracy. The relative positions of the satellites could be maintained with only small daily adjustments, Rosen says. Because the satellites within a cluster are so closely grouped, they would be able to observe the same location on the ground within a half second of each other, which allows effectively simultaneous measurements even under rapidly changing weather conditions.

The TRW scientists are scheduled to release their report at a meeting of the International Astronautical Federation in

\section{Lizzie home safe}

\section{London}

Lizzie, the fossil of the earliest-known reptile (see Nature 342,$676 ; 1989$ ), now has a secure home at the National Museums of Scotland. The announcement comes after the successful conclusion of an appeal to prevent the Scottish fossil from being sold by its discoverer, Stan Wood, to the Museum für Naturkunde in Stuttgart.

Wood and the Stuttgart museum had agreed to suspend the sale until 31 July in order to give the National Museums of Scotland a chance to raise the $£ 205,000$ purchase price. A last-minute donation of $£ 40,360$ by the National Heritage Memorial Fund and another $£ 20,000$ from West Lothian District Council made up the price, following the lead set earlier this year by the $£ 10,500$ contribution from the Geologist's Association which prompted Wood to drop the price by the same amount (see Nature 345, 99; 10 May 1990).

This intensive wheeling and dealing, unprecedented in the quiet world of vertebrate palaeontology, has now reached a satisfactory conclusion that will allow Lizzie to be given a formal geological name. The proposal is Westlothiana curryi, in recognition of the fossil's place of origin and the part played by West Lothian District Council and the Curry fund of the Geologist's Association in securing the fossil for Scotland. Henry Gee

October in Dresden, West Germany.

Shelby Tilford, director of NASA's earth science and applications division which runs the EOS programme, says that a switch to small satellites at this point would constitute a "new start" and could mean as much as a four-year delay in the project. A 1989 NASA study estimated that small satellites would cost $10-20$ per cent $(\$ 4,000-\$ 8,000$ million) more than the planned large platforms. But the AlAA report warns that "the theoretical cost advantage claimed for large programs typically turns out, in practice, not to be realized because the amount of coordination ... they require seems always to exceed the original projections". Big systems tend to be clumsy", it adds.

In April, an interim report from the National Academy of Sciences recommended that NASA investigate further the possibility of multiple small satellites as an alternative to its current EOS plans, at least for the second half of the project (see Nature 344, 578; 1990). Panel members say that the final version of the report, due out later this year, will conclude that NASA's arguments for three large platforms for the first half of the programme are "overwhelming", but that technical reasons for large - rather than small - platforms for EOS's second half are much weaker.

G. Christopher Anderson 